\title{
ESCOLA, DISCURSO, MÍDIA E VIOLÊNCIA UMA EXPERIÊNCIA EM BELÉM DO PARÁ
}

\author{
Ivânia dos Santos Neves é doutora em Linguística / Análise do Discurso pela UNICAMP, Coordenadora do Programa de Pós-Graduação em \\ Comunicação, Linguagens e Cultura da Universidade da Amazônia. \\ E-mail: ivanian@uol.com.br
}

Liliane Afonso de Oliveira é Graduada em Letras, Mestranda do Programa de Pós-Graduação em Comunicação, Linguagens e Cultura da Universidade da Amazônia. Atualmente é integrante do grupo de pesquisa do Projeto Observatório de Violência nas Escolas - Brasil Núcleo Pará

\section{Resumo}

Nas duas últimas décadas, os índices de violência em ambientes escolares aumentaram significativamente. Nos jornais de maior circulação na cidade de Belém, na Amazônia, não é difícil encontrar notícias sobre alunos que praticaram atos de violência e nestas matérias, há uma recorrência de conflitos que acontecem em escolas públicas. Esta situação leva, equivocadamente, a acreditar que a violência é uma característica particular destas escolas. O fenômeno da violência, no entanto, como as pesquisas já exaustivamente demonstraram, não é restrito a nenhuma classe social e atinge a sociedade como um todo. Tomando como referência teórica a análise do discurso, mais especificamente as reflexões de Michel Foucault e a partir dos resultados do projeto "Manejo de Conflito nas Escolas", desenvolvido por docentes da UNAMA, esta artigo pretende mostrar como a mídia local, uma escola particular de classe média e uma escola pública materializam os discursos sobre a violência na escola.

\begin{abstract}
In the last two decades, rates of violence in school settings have increased significantly. In major newspapers in the city of Belem, the Amazon, it is not difficult to find news about students who engaged in acts of violence and these matters, there is a recurrence of conflicts that happen in public schools. But the phenomenon of violence, as research has exhaustively demonstrated, it is not restricted to any social class and affects the entire society. Taking as the theoretical framework of discourse analysis, specifically the ideas of Michel Foucault and from the results of the project "Conflict Management in Schools", this article aims to show how the local media, a private school and a middle class public school materialize discourses on violence in school.
\end{abstract}

\section{1. “Deu no Jornal": para começo de conversa}

\begin{abstract}
Não basta saber ler que Eva viu a uva. É preciso compreender qual a posição que Eva ocupa no seu contexto social, quem trabalha para produzir a uva e quem lucra com esse trabalho.
\end{abstract}

Paulo Freire

Amazônia, cidade de Belém, 2001: estudante baleado dentro da sala de aula de uma escola da rede pública estadual. A notícia ganha grande destaque na imprensa. $\mathrm{O}$ aluno foi atingido por uma bala de um revólver que caiu no chão e disparou. Esta arma foi levada para a escola por uma aluna com o objetivo de assustar uma colega que, segundo ela, "roubou o seu namorado" (O Liberal 27-04-2001). 
Em outra escola da rede estadual, uma semana após ter ocorrido o baleamento do estudante na sala de aula, um adolescente disparou um tiro paro o alto, causando pânico entre os alunos. "O tiro foi dado como advertência para um aluno que brigou com o primo do autor do disparo, visto que este não conseguiu alcançar o advertido, pois ele foi protegido pelo porteiro da escola, que trancou o portão". (O Liberal 4-52001).

No ano de 2008, no bairro de Val-de-Cães, na cidade de Belém, uma aluna de 15 anos foi morta com duas facadas dentro de uma escola pública de Ensino Fundamental e Médio por uma colega de 18 anos de mesma série ( $8^{\text {a }}$ série). Alguns veículos de comunicação colocaram em circulação informações que levavam a acreditar que a menina que cometeu o crime era "perigosa" e que a escola também seria uma instituição "perigosa". Segundo o Amazônia Jornal de 18 de junho de 2008:

segundo informações apuradas pela reportagem e ainda não confirmadas, Edilene (a aluna agressora) já teve passagens pela polícia quando era menor de idade. Também surgiu a informação que há traficantes na família da acusada, mas isto ainda não foi confirmado.

Este jornal, conhecido por suas matérias apelativas, começa a expor a identidade da acusada, vai selecionando as informações mais sensacionalistas e desconsidera totalmente as condições de produção em que aconteceu a lamentável situação. Há algum tempo, porém, como outros poucos jornais noticiaram, as adolescentes tinham problemas uma com a outra e a escola já sabia dos problemas entre as alunas.

Alguns alunos e funcionários aproveitaram a repercussão e a revolta por conta do crime para realizar outras denúncias. Reclamaram principalmente sobre as condições físicas da escola, o policiamento escolar e o policiamento da área, onde é comum acontecerem assaltos.

A conclusão desta situação é que a escola embora até soubesse da situação entre as duas alunas, não agiu, não estabeleceu medidas disciplinares que coibissem este tipo de atitude. A ineficiência da escola, que pode ser explicada por muitas razões, que vão do salário do professor, passando pelo número insuficiente de orientadores escolares até a precária infra-estrutura, tem bastante responsabilidade pelo acontecido.

No ambiente escolar, local onde, supostamente, os alunos deveriam desenvolver a sua autonomia, senso critico e liberdade de expressão, isto não acontece. Muitas vezes, a escola torna-se um espaço limitado, padronizado por um certo processo de desenvolvimento, que acaba transformando-a em uma instituição apenas reprodutora das desigualdades sociais do país.

Por outro lado, as matérias sensacionalistas, que, sem nenhum pudor, exploram a violência impressa nos corpos de alunos das escolas públicas, reforçam o discurso de que a escola pública e seus alunos são violentos. 
O corpo, em sua visibilidade, posiciona discursivamente o sujeito, sobrederminando seu dizer, direcionando os sentidos e determinando as formas de relação inter-pessoal. Compreendido como espessura material significante, o corpo é a forma, o espaço e o texto nos quais o sujeito se simboliza, se representa e é representado, é a linguagem em toda sua força constitutiva no sujeito, em seus aspectos de opacidade, de contradição, de equivocidade. (HASHIGUTI: 2008, p. 71)

Socialmente, os alunos de escola pública passam a carregar sentidos bastante negativos e já começam a ser aceitos como "violentos". É, sem dúvida, um grande desafio para a escola pública conseguir administrar esta situação, que por vezes, ela mesma acaba reforçando, quando não consegue evitar as situações de violência, nem tampouco proteger seus alunos da exposição impiedosa da mídia.

Conhecer os manejos desses conflitos é um desafio pedagógico que vai além da dimensão ensino-aprendizagem. Lidar com conflitos no espaço escolar deveria compor as competências e habilidades na formação de gestores e professores. É urgente o redimensionamento de uma política de formação de docentes e gestores, e na qualificação de ações sócio-pedagógicas do espaço escolar. Todos estes atores, que compõem o universo escolar, deveriam ter uma estrutura propícia para poderem desenvolver estas competências e habilidades.

Nas duas últimas décadas, os índices de violência em ambientes escolares aumentaram significativamente. Nos jornais de maior circulação no estado do Pará, não é difícil encontrar notícias sobre alunos que praticaram atos de violência e, nestas matérias, há uma recorrência de conflitos em escolas públicas, o que levaria equivocadamente a acreditar que a violência é uma característica das escolas voltadas à população mais pobre. O fenômeno da violência, no entanto, como as pesquisas já exaustivamente demonstraram, não é restrito a nenhuma classe social e atinge a sociedade como um todo.

Além de considerar a posição dos principais jornais impressos em circulação na cidade, este artigo analisa a fala de alguns alunos da rede pública e privada de Belém. Estas falas são alguns resultados da pesquisa "Manejo de Conflitos nas Escolas: Interface entre escola pública e privada" que aconteceu em 2006 e abrangeu quatro (04) instituições de ensino, desenvolvida por docentes da UNAMA - Universidade da Amazônia. Esta pesquisa teve como principal objetivo compreender e comparar como as escolas manejam os conflitos e as violências ocorridas em seu interior.

Tomando como referência teórica a análise do discurso, mais especificamente as reflexões de Michel Foucault e a partir dos resultados obtidos no projeto "Manejo de Conflitos na escola", este artigo pretende mostrar como a mídia local, uma escola particular de classe média e uma escola pública materializam os discursos sobre a violência na escola.

\section{Sobre Belém}


Belém é um município brasileiro, capital do estado do Pará, considerada a maior cidade na linha do Equador, a segunda cidade mais populosa da região Norte e sede da segunda maior região metropolitana da Amazônia. Com uma população de 1392031 habitantes (IBGE/2010), é conhecida como "Metrópole da Amazônia". Situada às margens da Baía de Guajará é o principal portão de entrada da bacia Amazônica.

Belém está entre as dez cidades mais movimentadas e atraentes do Brasil. Tem a agitação das grandes cidades, mas, por sua geografia privilegiada, cercada por rios e pela baía, ainda guarda uma intensa relação com as paisagens naturais da região. A população da cidade é bastante heterogênea, formada, principalmente, por descendentes de portugueses, de africanos e dos índios Tupinambás, nativos habitantes da região à época da fundação.

No cenário da comunicação, a cidade conta hoje com 06 grandes emissoras de televisão, dois grandes jornais impressos, emissoras de rádio FM e AM e dois provedores de banda larga, que já levaram a internet a cabo para todas as regiões da cidade. As redes sociais já começam a demarcar um espaço considerável, principalmente entre os jovens e já não se pode estabelecer uma diferença de acesso em função de classes sociais, pois, nas áreas de periferia da cidade, os jovens acessam de espaços públicos, quer sejam as salas de internet nas escolas, quer sejam nas lan houses espalhadas por todos os bairros da cidade.

A Grande Belém configura-se, hoje, como o maior aglomerado urbano da região, visto que sua expansão urbana gerou um crescimento geográfico vertiginoso, atingindo uma população de 2,1 milhões de habitantes. Belém possui o maior IDH (Índice de Desenvolvimento Humana) entre as capitais nortistas. Segundo o oficial de coordenação da ONU no Brasil, Jean Bernardini, o IDH é "a contrapartida do desenvolvimento para além do PIB [produto interno bruto]". Com este índice, a ONU analisa não apenas o crescimento econômico de uma cidade, estado ou região, mas a qualidade de vida que esses locais apresentam.

As principais atividades econômicas da cidade estão voltadas para o setor de serviços. Há quatro grandes universidades na cidade e três grandes shopping centers que movimentam intensamente o comércio na região. A produção industrial é quase inexistente e não há nos espaços da cidade atividade agrícola consistente. O que significa que o mercado de trabalho também é bem restrito. De forma geral, a oportunidade de empregos para os jovens é bastante escassa.

Segundo estudos de Araujo (2008, p. 21):

Na última década, a Cidade de Belém, com mais de 2.116 milhões de habitantes (IBGE, 1990), concentrava quase 900 mil pessoas abaixo da linha de pobreza, o que correspondia $43,96 \%$ da população, ou seja, quase um milhão de pessoas sobreviviam com o equivalente hoje a $\mathrm{R} \$ 175,00$ (cento e setenta e cinco reais) por mês. Entre 2004 e 2005, o aumento do contingente populacional abaixo da linha da pobreza foi de 12,56\% no Estado do Pará e de 4,84\% na Cidade de Belém. Ainda em 2005, nada menos que $48 \%$ da população ocupada no Estado do Pará estavam no mercado informal, quer dizer, haviam mais de 1,5 milhão de pessoas nessa condição. Pior, mais 
de um terço da população ocupada, que é de 3,1 milhões, ganha no máximo um salário mínimo por mês. Na Cidade de Belém, em 2005, cerca de 400 mil pessoas, ou metade da população ocupada, estavam no mercado informal. Além disso, havia quase 130 mil "desocupados", o que equivalia a mais de 12\% da PEA (População Economicamente Ativa). Isso significa que mais da metade dos trabalhadores da Cidade de Belém, ocupados ou desocupados, sobreviviam em condições precárias, sem quaisquer direitos sociais ou trabalhistas.

Nos últimos 20 anos, as políticas públicas não enfrentaram esta situação e houve pouco investimento na educação e na segurança pública. Tampouco se criaram estratégias para fomentar a criação de novos mercados de trabalho na cidade. Diante deste cenário, os índices de violência alcançaram níveis alarmantes, a falta de perspectiva e a impunidade criaram na cidade uma grande sensação de insegurança. A desigualdade social parece dividir a cidade: existe uma Belém que vive os benefícios tecnológicos do início do século XXI, com seus computadores sofisticados, seus carros confortáveis, seus apartamentos de luxo e uma outra, em que boa parte da população não tem direito a nada.

A questão da violência urbana não pode mais deixar de ser observada somente do ponto de vista policial, pois não se podem responsabilizar os órgãos de segurança pública e simplesmente lamentar o número de vítimas. O problema afeta a sociedade como um todo, portanto a insegurança é uma questão social.

Belém é uma cidade da América Latina, de fortes contrastes econômicos e sociais, apresentando grandes disparidades entre ricos e pobres, uma cidade híbrida. Naturalmente, todos estes elementos constitutivos também se traduzem na realidade das escolas da cidade.

\section{Sobre o projeto}

O Observatório de Violências nas Escolas - Brasil / Núcleo do Estado do Pará desenvolveu a pesquisa com o título "Manejo de Conflitos nas Escolas: Interface entre escola pública e privada" que aconteceu em 2006 e abrangeu quatro (04) instituições de ensino: uma escola pública estadual, no centro nobre da cidade, uma escola particular laica de classe média, uma escola particular católica de classe média e uma escola particular evangélica de classe média.

Esta pesquisa teve como principal objetivo compreender e comparar como as escolas em questão manejam os conflitos e as cenas de violência ocorridas em seu interior. Partiu-se do princípio que estas dificuldades e limitações se constituem em fator de entrave à qualidade do ambiente escolar enquanto lócus privilegiado de desenvolvimento do cidadão. Os sujeitos do universo escolar que participaram foram os professores, a equipe técnica, diretor(a) e alunos do ensino médio.

Embora a pesquisa tenha alcançado um expressivo número de dados quantitativos e qualitativos, neste artigo, pelos seus limites, serão analisadas apenas 
duas situações narradas por alunos da escola particular laica de classe média e da escola pública.

Estas falas foram registradas utilizando-se da técnica de grupo focal, objetivando aprofundar o conhecimento sobre os sujeitos da pesquisa. O grupo focal é uma técnica de pesquisa ou de avaliação qualitativa, não-diretiva, que coleta dados por meio das interações grupais ao se discutir um tópico sugerido pelo pesquisador/entrevistador. Ocupa, como técnica, uma posição intermediária entre a observação participante e a entrevista de profundidade. O mais importante é a interação entre os participantes.

\section{Movimentação de Sentido nas Escolas}

A língua penetra na vida através dos enunciados concretos que a realizam, é é também através dos enunciados concretos que a vida penetra na língua.

Mikail Bakhtin

As falas dos alunos da escola pública e da escola particular de classe média colocam em circulação uma série de discursos que deixam evidências sobre o lugar social de onde falam e sobre suas práticas discursivas em relação à violência. É possível observar, a partir destas falas, como o discurso sobre a violência na escola dialoga com a mídia, atravessa os corpos destes alunos, perceber o que eles silenciam, quais são as interdições sobre o tema e como funcionam as estratégias das escolas que procuram, ou não, evitar as situações de violência, ou que atuam no sentido de puni-las.

O discurso é uma construção social de enunciados que caracterizam o modo de agir ou de pensar de alguém ou de um grupo específico. Essa construção, não individual, e que só pode ser analisada considerando seu contexto histórico-social e suas condições de produção traduz a visão de mundo do homem através de seu discurso, então, constituído por muitas falas e muitos dizeres, que são determinados pelas regras sociais de comunicação, pelas condições de produção históricas e por regras e convenções sociais.

Não se pode dizer tudo o que se quer, quando se quer, da maneira como se quer, com quem se quer. Há regras sociais que determinam o que pode e o que não pode ser dito pelas pessoas, nas diferentes situações e nos diferentes lugares. Como as pessoas, as instituições e as regras sociais mudam no decorrer do tempo, os discursos também vão sofrer modificações em função de acontecimentos históricos, de mudanças sociais, de interesses políticos e de relações de poder.

Para Foucault (2007, p. 5):

A verdade é deste mundo; ela é produzida nele graças a múltiplas coerções e nele produz efeitos regulamentados de poder. Cada sociedade tem seu regime de verdade, sua "política geral" de verdade: isto é, os tipos de discurso que ela acolhe e faz funcionar como verdadeiros; os mecanismos e as instâncias que permitem distinguir os 
enunciados verdadeiros dos falsos, a maneira como se sanciona uns e outros; as tendências e os procedimentos que são valorizados para a obtenção da verdade; o estatuto daqueles que têm o encargo de dizer o que funciona como verdadeiro.

As falas dos alunos são resultado de conjuntos discursivos que lhe são anteriores e que foram por ele internalizados em função da questão sócio-histórica a que todos estão submetidos. Filiam-se a uma memória discursiva. Para Courtine (1981, p. 72): "toda produção discursiva se efetua em determinadas condições conjunturais de produção e remete, põe em movimento e faz circular formulações anteriormente já enunciadas, como um efeito de memória na atualidade de um acontecimento".

Assim, em suas falas, os alunos colocam em circulação uma memória discursiva que retomam outros acontecimentos, como por exemplo, as matérias dos jornais sobre violência, os noticiários da TV. Elas constituem suas condições de produção na atualidade e mostram a que memórias discursivas eles estão filiados.

\section{1. "A primeira que saísse, elas iriam furar..."}

\section{É pelo estudo dos mecanismos que penetram nos corpos, nos gestos, nos comportamentos, que é preciso construir a arqueologia das ciências humanas.}

Michel Foucault

Na fala a seguir, uma situação narrada por uma aluna da rede pública mostra de que lugar social ela fala. A seleção dos acontecimentos, a seleção das palavras e até mesmo a falta de interdição em relação ao corpo, que pode a qualquer momento ser exposto à violência, aos poucos, vão revelando a forma como ela se situa no mundo.

\footnotetext{
"Uma vez, a gente jogou bola aqui no colégio de tarde. Era apostando dinheiro, só que ninguém sabia, os diretores, ninguém, era tudo escondido. Eram as meninas do colégio $\mathrm{X}$ contra nós. Na hora de pagar, as meninas daqui perderam e não quiseram pagar e começaram a dizer que não poderiam pagar, porque não podia fazer jogo apostando dentro da escola. Mas se elas ganhassem, elas iriam querer o dinheiro.

As meninas do colégio $\mathrm{X}$ ameaçaram furar a gente, elas esperaram a gente aí fora. A primeira que saísse elas iriam furar. A gente teve que ficar até a noite, o diretor chamou a polícia e disse que a gente só deveria sair quando a polícia chegasse. A gente falou que não ia ficar porque, eu pelo menos, não tinha nada a ver com isso. Eu falei pra ele que eu ia embora, porque o dinheiro da aposta estava todo na mão de uma menina, essa menina pegou e foi embora escondido, foi pra casa dela, ela quem puxou a briga e deixou a gente aí. A gente foi lá pro campo, essas meninas começaram a falar que elas iam furar a gente. Porque elas não eram molecas pra gente fazer isso com elas. $\mathrm{O}$ diretor quis interferir, mas as alunas não deixaram. Às vezes, eles tentam ajudar, mas a gente não colabora".
}

A escola é uma das mais importantes instituições sociais. Acredita-se que, nela, os jovens viveriam em segurança. Os professores e a equipe técnica, em tese, 
acompanhariam os principais movimentos dos alunos no espaço escolar. Embora a narrativa da aluna materialize uma realidade bastante inesperada, as expectativas sociais, em relação à escola, incluem estratégias de controle dos acontecimentos em que os alunos estariam envolvidos.

Em Vigiar e Punir (2009), Michel Foucault faz uma dura crítica às escolas francesas autoritárias, analisando aquilo que ele chama de "docilização dos corpos". Regras muito austeras e por vezes extremamente autoritárias fizeram parte do cotidiano escolar por muitos séculos, tanto na Europa, como no Brasil. Os mecanismos de controle eram bastante opressores e os de punição extremamente violentos, que iam desde violência verbal, até os castigos físicos.

Foucault chamava as escolas - assim como os hospitais, as prisões, os asilos e as fábricas - de "instituições de seqüestro" (Foucault, 2009, p. 114). Para ele, as escolas tinham como finalidade não excluir, mas, ao contrário, fixar os indivíduos em um grupo, e tinham como prioridade implicar o controle e a responsabilidade sobre a totalidade ou a quase totalidade do tempo dos indivíduos. As indústrias os ligavam, por exemplo, a um aparelho de produção e a escola a um aparelho de transmissão do saber. Essas instituições tinham basicamente três funções: a primeira era fixar os indivíduos em um aparelho de normalização dos homens; a segunda, controlar os corpos desses indivíduos, transformando-os em força de trabalho; e a terceira função consistia na produção de um poder que mantivesse a ordem social.

Com relação à questão do controle disciplinar desempenhado nas escolas, Foucault (2009) apresenta a arte das distribuições para o controle disciplinar, demonstrando como diferentes técnicas eram, em épocas passadas, utilizadas também na escola para vigiar e punir os alunos:

A primeira técnica é a da cerca, na qual a idéia do enclausuramento de si próprio, dentro de uma organização física, demonstrava a disciplina da instituição; uma outra arte de controle era a da localização imediata, com cada indivíduo em seu lugar e, em cada lugar, um indivíduo; para finalizar a questão do controle, cito a organização seqüencial das carteiras nas salas de aula. Essa organização fez com que o espaço escolar funcionasse como uma máquina de ensinar e também de vigiar, de hierarquizar e de recompensar. (FOUCAULT, 2009, p. 121-127)

Baseados nestas críticas de Foucault, uma série de trabalhos na educação seguiram criticando sistemas educacionais repressores, que não permitiam a criatividade de professores e alunos. O que se observa hoje, no entanto, é que em algumas situações, parece que a escola migrou para o lado oposto deste cenário.

A situação relatada pela aluna da escola pública deixa ver que, se por um lado a escola não impõe regras de condutas rígidas, por outro, não tem suas próprias estratégias para estabelecer uma estrutura mínima de convivência em seu espaço. Não há um cerceamento austero da conduta dos alunos, nem tampouco normas flexíveis. Parece evidente que a escola não consegue cumprir com o seu papel. 
A escola em que aconteceram os fatos narrados é uma das maiores escolas públicas da cidade, funciona em três turnos: manhã, tarde e noite, com mais de dois mil alunos regularmente matriculados. As salas iniciam o ano com mais de 40 alunos. A maioria dos professores trabalha em mais de uma, de duas ou até mesmo de três escolas da rede pública. Uma parte destes professores possui contratos temporários e muitas vezes, não passam mais do que um ano letivo na escola. A equipe pedagógica, por sua vez, resume-se ao diretor, a uma vice-diretora e a duas orientadoras educacionais. Com este quadro tão reduzido, não se pode esperar uma escola envolvida de perto com as práticas sociais dos alunos, nem mesmo com aquelas que acontecem no espaço escolar.

As iniciativas positivas que acontecem nesta escola são em função de atitudes isoladas de professores, que mesmo com um cenário tão desfavorável, resolvem fazer a diferença. O que aparece nos discursos dos alunos entrevistados revela como esta escola está desestruturada para tratar do manejo de conflitos em seu espaço.

Alunas de outras escolas estavam na quadra de esporte. $\mathrm{O}$ que significa que o acesso às dependências da escola é livre. Era uma competição esportiva, em que apostaram dinheiro e não havia um professor de educação física, nem alguém da equipe pedagógica da escola. Durante o jogo, alguma situação mais violenta poderia tranquilamente virar uma tragédia. Nem mesmo a presença do diretor, depois que aconteceu o conflito entre as alunas, conseguiu contornar a situação. Foi necessário chamar a polícia e as alunas da escola não obedeceram ao que ele estabeleceu. A situação que se seguiu ao jogo poderia ter terminado em uma manchete de algum jornal sensacionalista.

O funcionamento de uma escola deveria ser regido por normas e regras que valorizassem não apenas a interação de cada aluno na sala, mas também a convivência social dele com as outras turmas e com a instituição como um todo.

\section{2.“Quem vai olhar se tu fizeste são os teus pais"}

A narrativa a seguir foi feita por uma aluna de escola particular de classe média e revela um cenário absolutamente diferente:

"Eu vou contar o caso desse nosso amigo, que pegou essa detenção. Esse nosso amigo que pegou essa detenção já tinha ido pra coordenação tantas vezes que já era uma coisa cômica, já era engraçado. Ele até brincava que ele já era "vip" e tal. Ele mesmo, quando mandavam ele sair pra fora de sala, ele já saia rindo e a gente já ria e o professor acabava rindo e às vezes nem tirava ou até esquecia que tinha que tirar.

Então, foi muito legal essa questão que eles levantaram, dessa detenção, do aluno em vez de ser suspenso, no caso do ensino médio, ele sofrer isso, de ir pra biblioteca e ter que fazer resumo de 3 matérias. Mas eu acho que o melhor ainda é que ele agora age com muito medo, porque o colégio chamou a mãe e o pai dele e falou assim: "Tu não vais ser supervisado pela gente, mas pelos teus pais! Quem vai olhar se tu fizeste são os teus pais. E tem outra coisa: se tu fizeres mais alguma besteira são os teus pais que vão ser responsáveis". Aí depois ele falou assim: "E tem outra coisa, tu vais descer e conversar com a X (diretora da Escola), a diretora do colégio.” Aí o nosso coração... 
"Bababababa!!!", já bate mais forte. Pô é a x (diretora da Escola), ela tem todo o direito de expulsar a gente do colégio, de pedir pra se retirar.

Ele ficou com medo, aí ele mesmo já chega na coordenação e fala: "Por favor A, por favor, B, liga pra mamãe e diz que já tô me comportando!”.

Os nossos pais já tão punindo a gente dentro de casa, por causa dessa detenção que eles criaram nova.

Ele faz assim: "Faz a minha capa pra minha mãe agora, porque eu tenho uma festa sábado".

Gente! Ele já começou a pedir pra ir na coordenação, pra coordenação conversar com os pais dele, porque ele tá sendo punido dentro de casa, era uma coisa que não era sabe?

A gente ia pra coordenação.. aí tu: "Ahhh!! Vou ser suspenso por dois dias", aí ficava em casa dois dias dormindo.. e pros pais ele tava dormindo mesmo.. os pais nem falavam, né? Agora não".

Pela fala da aluna, pode-se perceber que a equipe de profissionais que compõe a equipe pedagógica conta com coordenadores e psicólogos, além da direção e dos professores. É possível observar que a escola fica experimentando novas estratégias para evitar situações de violência entre os alunos. Inclusive, se tomada isoladamente, esta fala até pode levar a pensar que há muita rigorosidade por parte da escola. A aluna usa a palavra "punição", mas em outras falas, percebe-se que as regras não são tão rigorosas assim.

No discurso que os alunos desta escola colocam em circulação, a presença da equipe pedagógica está bastante em evidência. Eles narram muito pouco as situações de violência, que sempre aparecem de forma bastante atenuada. O foco é a negociação com a equipe pedagógica e com a família, que é sempre convidada a participar.

Analisando estas falas é possível perceber uma certa interdição em relação aos atos de violência. Mesmo numa época em que o bullying está presente em matérias constantemente exibidas pela mídia, as narrativas omitem qualquer tradução de violência que possa se materializar no corpo destes alunos.

O lugar social de onde falam não permite que se apresentem como pessoas violentas e muito menos que identifiquem na escola um lugar de violência, ainda que muitos casos de conflito entre alunos e professores aconteçam cotidianamente. Os professores e os técnicos também silenciam em relação a conflitos mais sérios, pois, ainda que esta "tranquilidade" dos alunos não seja a condição deles na escola, a posição em que se encontram pode ser ameaçada, se por alguma razão, os discursos em circulação sobre a escola em que trabalham forem associados à violência.

O aluno é também um cliente. Que família de classe média matricularia seu filho em uma escola violenta? Como estas famílias reagiriam se seus próprios filhos se considerassem pessoas violentas? Como estes filhos poderiam negociar com os pais, se se reconhecessem como pessoas violentas? A mídia, que também fala de lugares sociais muito bem estabelecidos, em relação a estas escolas, toma bastante cuidado.

\section{Considerações Finais}


A escola pública estadual apresentou um ambiente em péssimo estado de conservação, com salas pichadas, carteiras quebradas e riscadas, policiais dentro da escola fazendo uma espécie de ronda, grades. A sensação é que os alunos não pertencem àquele espaço, que por ser público, acaba sendo de ninguém. Esta falta de identificação dos alunos acaba se materializando nas próprias condições do prédio.

Ao contrário, a escola particular apresenta um ambiente em ótimo estado de conservação, com salas climatizadas, carteiras pintadas, bem conservadas. Diferente da escola pública estadual, na escola particular, não há nada que indique público em seu espaço. Nela, os alunos se sentem parte do espaço, como se não estivessem ali de passagem, à espera de um local melhor (defendem o espaço, protegem). O que não significa que nunca danifiquem a escola, mas, como se trata de uma escola particular, a manutenção não deixa ver estas marcas. Os alunos recebem tratamento de clientes: existe um cuidado dos professores e direção ao referirem-se aos alunos e suas famílias, o que não parece existir dentro da escola pública estadual.

Estas diferenças atravessam profundamente os discursos que os alunos colocam em circulação sobre a violência na escola. Não há interdição em relação à violência física: "as alunas do colégio x ameaçaram nos furar". De certa forma, esta fala dialoga com as manchetes sensacionalistas dos jornais. Para estes alunos, a agressão física é cotidiana e a sociedade aceita o sensacionalismo com que eles são tratados. Eles próprios aceitam.

$\mathrm{Na}$ escola particular, em nenhum momento, durante as entrevistas, fala-se sobre violência física de forma explícita. A violência que aparece nas falas dos alunos vem profundamente marcada por um silenciamento: não se fala do corpo e nem de agressões verbais mais sérias. Parece que os conflitos se restringem à relação professor x aluno. Será que nesta escola os alunos nunca se desentendem de forma mais séria? Tudo é absolutamente contornável pela equipe pedagógica, que tem muita intimidade com eles? Dá a impressão de que não há filhos de famílias desestruturadas, que eles não participam de uma sociedade marcada pela desigualdade e que não estão expostos aos discursos violentos exibidos pela mídia. Para Foucault (2007, p. 12):

Cada sociedade tem seu regime de verdade, sua "política geral" de verdade: isto é, os tipos de discurso que ela acolhe e faz funcionar como verdadeiros; os mecanismos e as instâncias que permitem distinguir os enunciados verdadeiros dos falsos, a maneira como se sanciona uns e outros; as tendências e os procedimentos que são valorizados para a obtenção da verdade; o estatuto daqueles que têm o encargo de dizer o que funciona com verdadeiro.

As situações analisadas neste artigo mostram como as diferenças sociais se traduzem na estrutura da escola. Embora os conflitos e a violência não estejam limitados a uma classe social, a forma como a sociedade olha para estas situações está atravessada por estas diferenças. $\mathrm{O}$ tratamento que os alunos recebem na escola particular, com uma equipe de profissionais voltada para criar estratégias que evitem a violência, embora não 
possa evitar totalmente, cria um clima muito mais amistoso dentro da escola. Orientadores, psicólogos, coordenadores são sujeitos fundamentais para criar um ambiente em que a violência não é institucionalizada.

Muito além dos muros da escola, este complexo fenômeno social a que se chama de violência atinge índices alarmantes. No Brasil, a violência é um fenômeno multideterminado e não pode ser circunscrita a determinados segmentos sociais, já que atinge a sociedade como um todo. Ela pode ser fomentada pela família desagregada, pelo crescente processo de exclusão social e econômica de grande parcela da população e, naturalmente, pelos discursos colocados em circulação naquele que nas últimas seis décadas tem sido o principal veículo de comunicação: a televisão, pois nela "está reunido o maior potencial de influência sobre o comportamento da criança e do adolescente" (AQUINO: 2000, p. 13).

São inúmeros os fatores que podem levar uma criança ou um adolescente a um ato delitivo. Estudá-los é de fundamental importância para desenvolver ações que vão prevenir e enfrentar o fenômeno da violência na sociedade como um todo e na escola mais especificamente. Muito embora já existam ações no sentido da prevenção, há que se considerar que o índice de violência nas escolas, tanto pública quanto privadas, recrudesce a cada ano.

\section{Referências Bibliográficas}

ARAÚJO. Jorge Wilson Pinheiro de. A Cartografia de Homicídios na Cidade de Belém: Bairros do Guamá, Terra Firme e Universitário. 2008. Disponível em $<$ http://www.segurancacidada.org.br/index.php?option=com_docman\&task=cat_view\& gid=71\&limit=10\&limitstart=0\&order=hits\&dir=ASC\&Itemid=293> Acessado em 03 fev. 2011.

AQUINO, Júlio Groppa. Educação e Violência. São Paulo, V.26, n.227.2000.

BAKHTIN, Mikail Mikhailovitch. Estética da criação verbal. São Paulo: Martins Fontes, 1992.

CAREgnATO, Rita Catalina et Aquino; MUTTI, Regina. Pesquisa qualitativa: análise de discurso versus análise de conteúdo. Florianópolis: 2006. Disponível em: <http://www.scielo.br/pdf/tce/v15n4/v15n4a17.pdf>. Acesso em: 15 out. 2009.

COURTINe, J.J. Analyse du Discurs Politique. Languages 62, 1981.

FARIAS, Edimar. Baleado na Sala de Aula. Jornal O Liberal. Belém, 27 de Abril. 2001. Caderno, p. 10.

FOUCAULT, Michel. Microfísica do poder. Rio de Janeiro: Graal, 2007.

Vigiar e Punir. Petrópolis: Vozes, 2009. 
HASHIGUTI, Simone. Corpo de Memória. Tese de Doutorado. Campinas: Unicamp, 2008.

AMAZÔNIA JORNAL. "Estudante mata colega dentro da sala de aula". Belém, 18 de junho 2008. p. 47-48.

SAMPAIO, Paula. "Tiro na frente de escola causa pânico". Jornal O Liberal. Belém, 04 de maio 2001. Atualidades, p. 9.

UFPA IMPRENSA. Seminário vai discutir a questão da violência em Belém. Belém, 22 de fevereiro 2007. Notícias. Disponível em <http://www.portal.ufpa.br/imprensa/noticia.php?cod=1040>. 